\title{
A Web based Observance and Alerting for Underground and Fish Pond Water Quality
}

\author{
V.Ramya \\ Assistant Professor \\ Dept of CSE, \\ Annamalai University, \\ Chidambaram, Tamil Nadu
}

\author{
V.Balaji \\ Research Scholar \\ Dept of CSE, \\ Annamalai University, \\ Chidambaram, Tamil Nadu
}

\author{
T. Akilan \\ Research Scholar \\ Dept of CSE, \\ Annamalai University, \\ Chidambaram, Tamil Nadu
}

\begin{abstract}
Water is one amongst the foremost necessary and basic natural resources. This approach of constant observance and alerting of underground and fish pond water shall promote the implementation of actions that will forestall human sickness caused thanks to consumption of poor quality of water and to develop health Fish Lake. This project proposes a sensing element primarily based pollution detection and alerting to the licensed agent via SMS and e-mail. The key parameters taken under consideration during this work are $\mathrm{pH}$ scale level, temperature, Dissolved Oxygen(DO) for fish lake water and therefore the water level, Total dissolved solids (TDS) were thought of for underground water. These parameters were detected by the corresponding sensors associated and are sent to the microcontroller unit wherever it is compared with the set point and invokes an alarm according it. The LCD display interfaces with the microcontroller unit to reveal this noninheritable parameter of water. Further, these parameters were sent to the base station through the wireless Zig-Bee communication module. Web site is maintained to store parameter of water and therefore the agent will read the water quality through web site (www.watermonitoringsystem.in). Once water parameter is not acceptable for drinking purpose then associate E-Mail and SMS alert is given to the user.
\end{abstract}

\section{Keywords}

DO, LCD, Microcontroller, Sensors, Zig-Bee technology

\section{INTRODUCTION}

We clean and plentiful water provides the inspiration for prosperous communities. We tend to consider clean water to survive; nonetheless straight away we tend to square measure heading towards a water crisis. Dynamic climate patterns square measure threatening fish pool, lakes and rivers, and key sources that we tend to faucet for water square measure being overdrawn. There square measure some ways to observe water conditions [1]. Observance specialists sample the chemical condition of water, sediments, and fish tissue to see levels of key constituents like dissolved chemical element, nutrients, metals, oil and pesticides. They conjointly monitor physical conditions like temperature, flow, sediments, and also the erosion potential of stream banks, fish pond and lake shores. Biological measurements of the abundance and type of hydrophyte and animal life and also the ability of take a look at organisms to survive in sample water also are wide wont to monitor water conditions.

\subsection{Existing Method}

The Existing technique of water quality testing is to gather samples manually then transport them to a research laboratory for analysis. The previous analysis has been done either in observance fish pond or underground water, there's no analysis has been engineered combining the each fish pond and underground water. The disadvantage of the previous analysis is that the parameters can't be monitored on the positioning and technique of alerting is obtainable through solely Short Message Service (SMS).The main disadvantage of the present system is that the parameters is viewed by unauthorized viewers and solely the present parameters square measure shown that lacks the user to check present parameters with the past parameters.

\section{RELATED WORKS}

Xiao Ying et al. [1] have projected a groundwater monitor style. It's composed to a take-off and landing negative feedback circuit by a water level monitor, a comparator IC and 89C51 single-chip. The automated recording devices combined with dynamic code have achieved a dynamic time period, accurate, continuous convenient observance of the groundwater.

Mo Deqing et al. [2] projected automatic menstruation and reportage system of water quality has been developed. After that, the information square measure in a flash sent to the observance center by GSM network within the style of SMS. If the water quality is abnormal, the information is sent to observance center and management's mobile within the same approach at a similar time. It's convenient for managing to require corresponding measures timely and be able to discover time period things of water quality remotely.

Zhang Feng et al. [3] have projected the planning of wireless device network and web technology of farmland automatic irrigation management technique. The ultimate analysis of the network on the web supported the agricultural plants of farmland water-saving irrigation system integrated approach. The user uses mobile phones or wireless organiser will simply soil wetness content of on-line observance and management to appreciate the irrigation automation.

Tushar Kumar Gandhi et al. [4] projected Water quality is usually unnoted within the pool or lake management, and poor water quality will result in common issues, like excessive protoctist blooms, overgrowth of plants, vesicant smells, or dead and dying fish. So as to forestall these issues, AN understanding of basic water chemistry and alternative physical parameters is critical.

Adinya John Odey et al. [5] projected unceasingly monitor aqua-environmental parameters then initiate AN alert or early warning to system user once bound thresholds square measure exceeded. The information generated from this method is keeping regionally on the entranceway or sent to a distant net server. Information on the native info or remote net server is accessed with good mobile phones or personal computers. 


\section{SYTEM DESIGN}

Online Water monitoring provides services wherever the underground water parameters (e.g., Water level and TDS) and fish lake water parameter (e.g., $\mathrm{pH}$ ) area unit subjective knowledge is collected by sensors, usually within the residence. This knowledge is transferred electronically to internet server who analyses, responds and stores the information using Zig-Bee technology. The online water observation and interactive devices permits the water parameter to be sent to the user on an everyday basis while not the necessity for travel. During this project the most hardware equipment's used are:

- Microcontroller (AT89C51),

- Sensors,

- $\quad$ Zig-Bee

The microcontroller sends the knowledge of the temperature, water level, $\mathrm{pH}$, TDS and DO of the water to the remote server through the Zig-Bee module. The data acquisition module is shown in Figure 1.

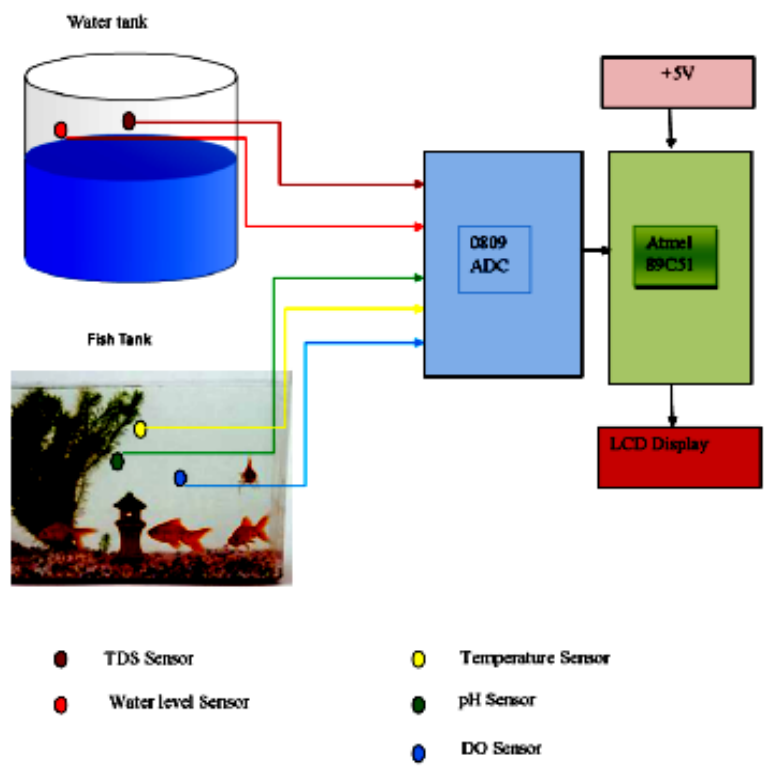

Fig. 1: The data acquisition module

The water quality monitoring through website is shown in Figure 2. The received data is viewed through the web site and additionally maintains the information in server.

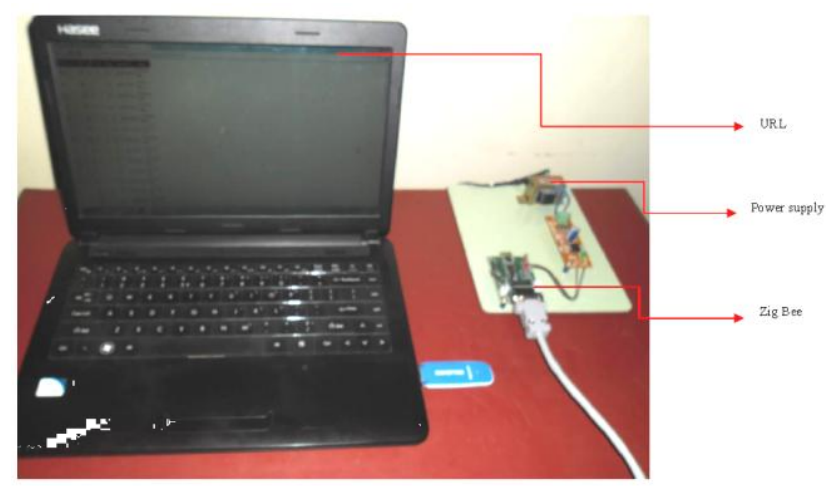

Fig. 2: Water monitoring through Web

\section{HARDWARE DESCRIPTION 4.1 Atmel 89C51 Microcontroller}

The AT89C51 could be a low-power; superior CMOS 8-bit personal computer with $4 \mathrm{~K}$ bytes of Flash programmable and erasable read only memory (PEROM) [2]. The device is factory-made victimisation Atmel's high-density nonvolatilizable memory technology and is compatible with the industry-standard MCS-51 instruction set and pin out.

\subsection{Temperature Sensor}

Resistance thermometers, additionally known as resistance temperature detectors ('RTD's), are sensors wont to measure temperature by correlating the resistance of the RTD part with temperature. Most RTD components encompass a length of fine twisted wire wrapped around a ceramic or glass core. The part is sometimes quite fragile, thus it's typically placed within a clad probe to safeguard it. This detector is placed in fish pond [3]. If the temperature of the pond water exceeds $32^{\circ} \mathrm{C}$ then the controller invokes alarm that states that the pond water temperature isn't appropriate for existence of fish (Figure. 3)

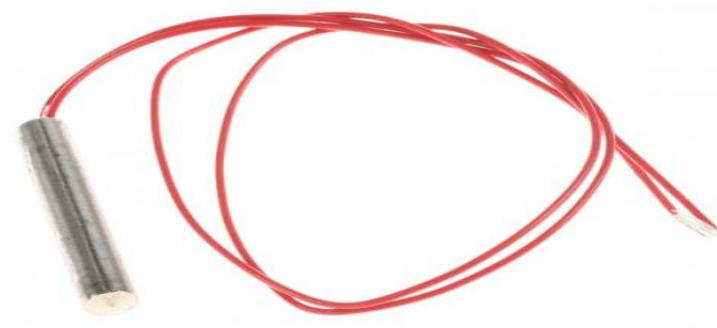

Fig. 3: Temperature Sensor

\subsection{TDS Sensor}

If water contains no soluble materials and is pure, it'll not conduct a charge and can so have a zero ppm. Conversely, if the water is packed with dissolved materials, it'll conduct a charge, with the ensuing ppm being proportional to the quantity of dissolved solids. This is often as result of all dissolved solids has associate degree electrical charge that permits electrical charge between the electrodes [4]. If TDS of the underground water exceeds the 1200 then microcontroller invokes associate degree alarm to state that the water isn't sensible for drinking purpose (Figure. 4).

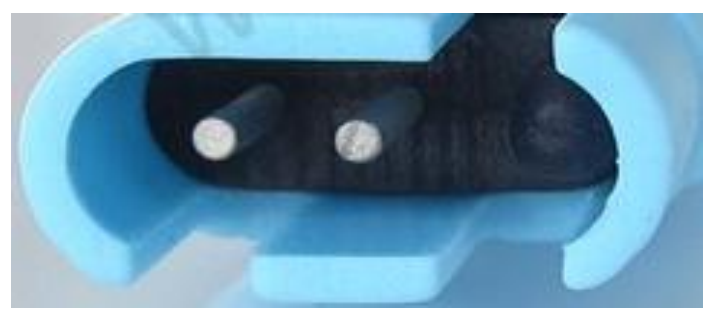

Fig. 4: TDS Sensor

\section{4 pH Sensor}

The measure conductor, that is sensitive to the proton, develops a possible (voltage) directly associated with the proton concentration of the answer [5]. This detector is placed in fish pond. If the $\mathrm{pH}$ of the pond water greater than 5 then the controller invokes associate degree alarm that states that the pond water $\mathrm{pH}$ isn't appropriate for existence of fish (Figure. 5). 


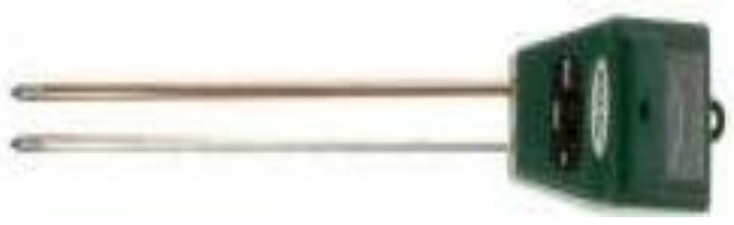

Fig. 5: pH sensor

\subsection{DO Sensor}

An element device is associate device that measures the proportion of element $(\mathrm{O} 2)$ within the water being analysed. Oxygen is required by fish and alternative aquatic organisms, and levels of DO can verify the flexibility of ponds and alternative water bodies to support aquatic life. Element dissolves in water at terribly low concentrations measured in components per million (ppm, which may be used interchangeably with milligrams per $1[\mathrm{mg} / \mathrm{L}]$ ) [6]. Ponds can seldom have over ten ppm DO (Figure. 6).

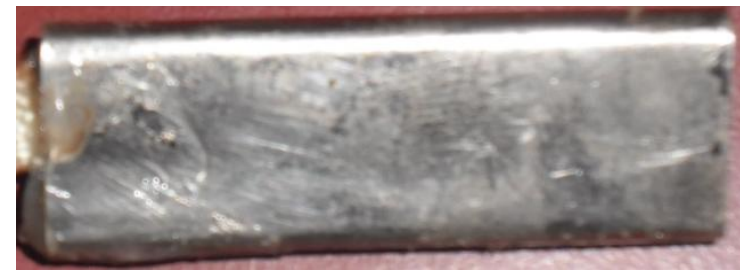

Fig. 6: DO sensor

\subsection{Water Level Sensor}

Water level sensors are just like float level sensors but a magnet combine is sealed within the float arm pivot, because the float moves up the motion and site are transmitted because the position of the force field [7]. This detection system is very correct all the way down to 0.02 Degrees of motion. Whenever the water level reduces into third then the microcontroller invokes the alarm (Figure. 7).

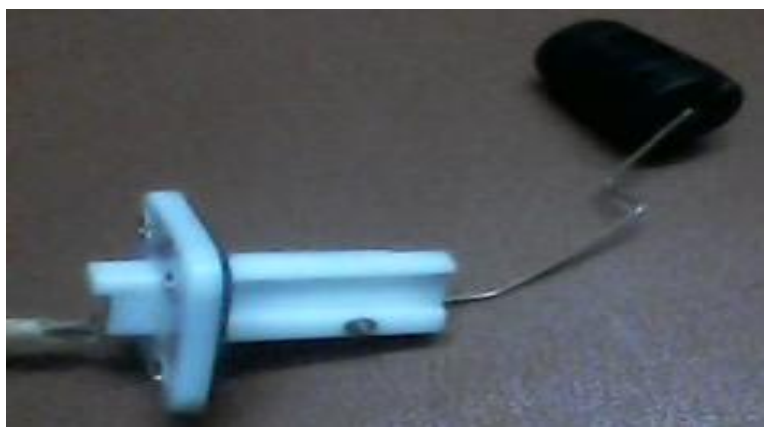

Fig. 7: Water level sensor

Table 1. The tolerable range of underground and fish pond water

\begin{tabular}{|c|l|l|}
\hline Parameters & $\begin{array}{c}\text { Tolerable range of } \\
\text { ground water }\end{array}$ & $\begin{array}{c}\text { Tolerable range } \\
\text { of fish pond water }\end{array}$ \\
\hline Temperature & $29-31 \circ \mathrm{C}$ & 26 to $32 \circ \mathrm{C}$ \\
\hline $\mathrm{PH}$ & $6.5-8.5$ & 6.5 to max 9 \\
\hline $\begin{array}{c}\text { Dissolved } \\
\text { oxygen(DO) }\end{array}$ & $>5 \mathrm{ppm}$ & $0-5 \mathrm{ppm}$ \\
\hline
\end{tabular}

\subsection{Buzzer}

The Buzzer is employed to sounds a warning within the kind of a nonstop or intermittent droning or beeping sound that states that the fish pond water and underground water isn't appropriate for consumption is shown in figure.8.

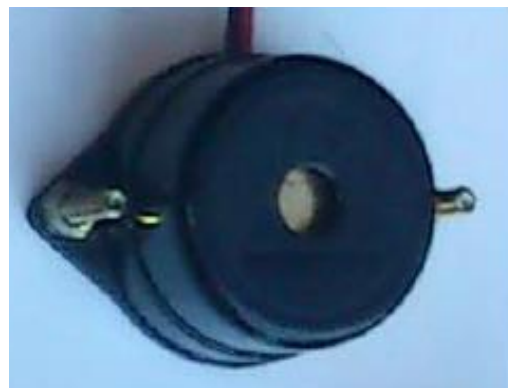

Fig. 8: Buzzer

\subsection{Zig-Bee}

Zig-Bee and IEEE 802.15.4 square measure standards-based protocols that offer the network infrastructure needed for wireless sensing element network applications. 802.15.4 defines the physical and mac layers, and Zig-Bee defines the network and application layers [8]. For sensing element network applications, key style necessities revolve around long battery life, low cost, secured, reliable and self-healing, simple and cheap to deploy, little footprint, associate degreed mesh networking to support communication between giant numbers of devices in an practical and multi-application surroundings.

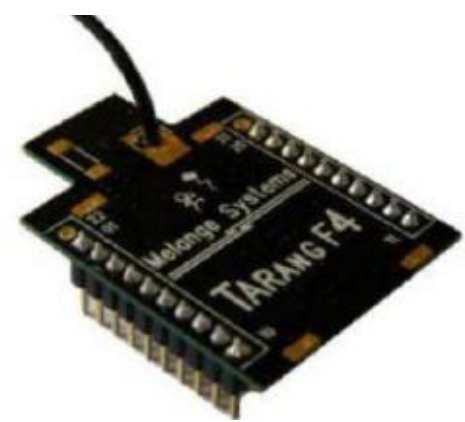

Fig. 9: Zig-Bee

\section{SOFTWARE DESCRIPTION}

\subsection{A51 Assembler}

The A51 computer program could be a macro computer program for the 8051 family of microcontrollers. It supports all 8051 derivatives. It interprets symbolic programming language method into relocatable code wherever the utmost speed, little code size, and hardware management square measure important. The macro facility speeds development and conserves maintenance time since common sequences would like solely be developed once [9]. The A51 computer program supports symbolic access to all or any options of the 8051 design. The A51 computer program interprets computer program supply files into relocatable object modules.

\subsection{Atmel Burner}

ATMEL eighty nine series 8051 USB applied coder user could be a full featured low value programmer for many common 8051 microcontrollers. The engineer works on USB port and might be used with Laptops. Programming or burning a microcontroller means that to transfer the program from the compiler to the memory of the microcontroller. A 
compiler is software package that provides associate degree surroundings to write down, check and rectify a program for the microcontroller. The program for a microcontroller is mostly written programming language. Finally the compiler generates a hex file that contains the machine language instruction intelligible by a microcontroller. It is the content of this hex file that is transferred to the memory of the microcontroller. Once a program is transferred or written within the memory of the microcontroller, it then works in accordance with the program (Figure.10).

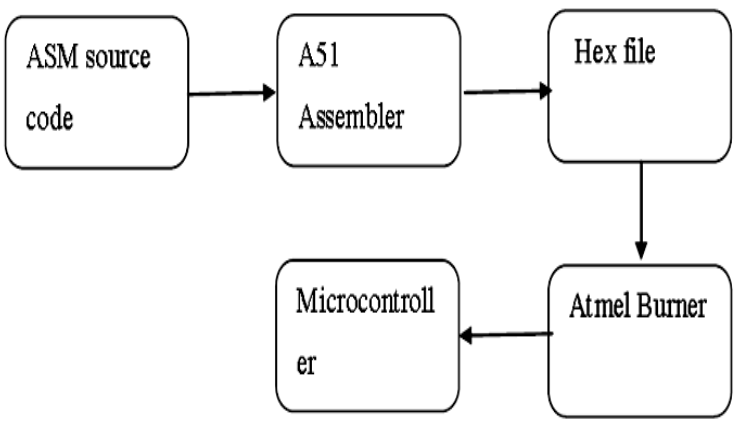

Fig. 10: Burning source code into microcontroller

\subsection{Building an Application in Flash \\ Programmer}

To build (assemble and flash program) an application in pgm 89 , the following steps must be performed.

STEP1: Open the notepad and type the required assembly language code.

STEP 2: Type the name of project file in extension .asm and save it.

STEP 3: Select the assembler A51 and enter project file to assemble.

STEP 4: After assembling the program stemp.hex file is produced.

STEP 5: To open stemp.hex in pgm89 flash programmer, select open file and select a file name.

STEP 6: Machine level language code is fitted into their address where it is displayed in flash programmer and loaded into the microcontroller by selecting the Write button.

\section{IMPLEMENTATION}

The embedded control unit is designed using AT89C51 microcontroller which interfaced with sensors, buzzer and zigbee. The parameters of water (Temperature, $\mathrm{PH}$, Water level, Dissolved Oxygen [DO], Total Dissolved Solids [TDS]) are sensed by corresponding sensors namely RTD PT 100, PH sensor, water level sensor, TDS sensor and DO sensor. Temperature sensor senses the temperature of the fish tank and send the current temperature value to the microcontroller. Similarly, the sensors like $\mathrm{pH}$, TDS and water level perceived are transmitted to the microcontroller via Zig-Bee. All the sensory information is monitored in local system. Prototype of data acquisition on remote area and the overall design are shown in the Figure. 11 and Figure.12

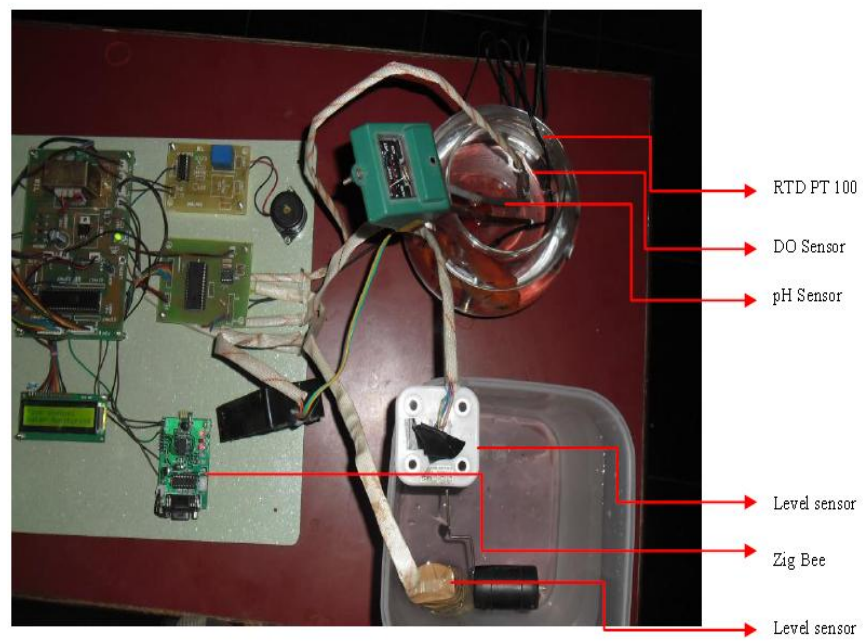

Fig. 11: Prototype of Data acquisition on remote area

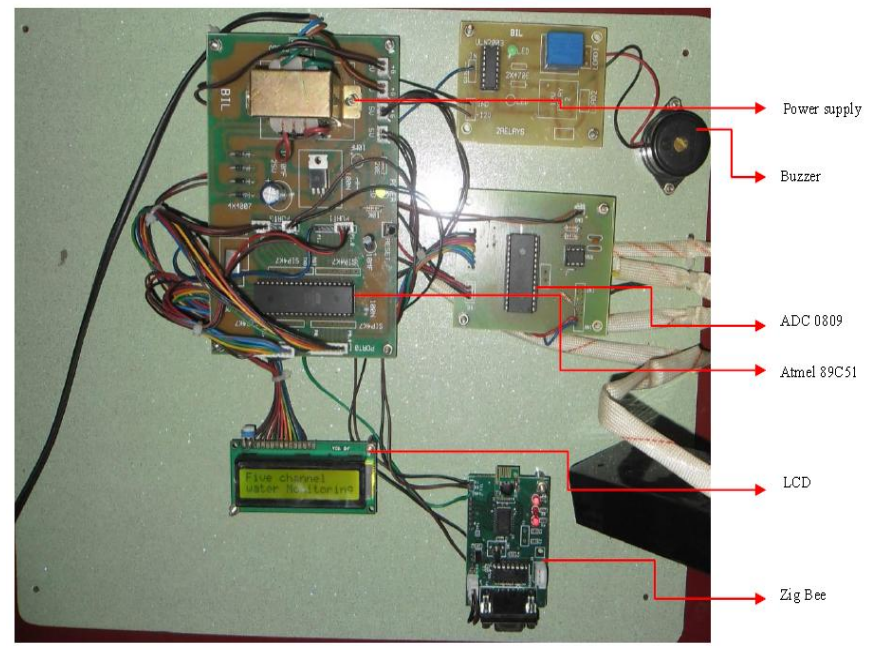

Fig. 12: Prototype of the overall design

Figure.13 shows the sql server information, where the user can monitor the sensors parameters lively in local system.

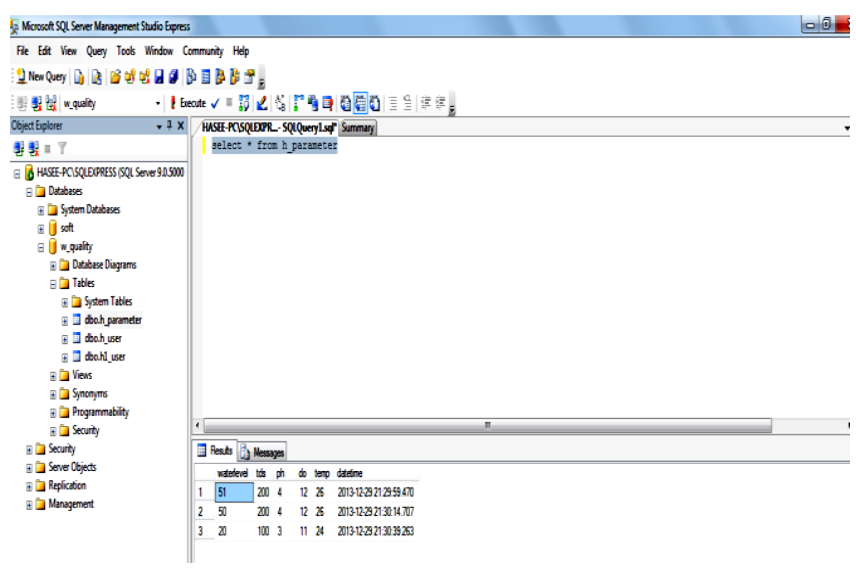

Fig. 13: sql server

\subsection{Online water monitoring system}

In Internet user can view the sensors parameter which resides at fish tank by login into the web site, by providing authenticated user name and password [figure 14]. The new user can also check the sensor parameter by simply enter into the site and made sign up procedure to access the information 
of water monitoring system. Once user name and password is made, Email and SMS is sent to the new user for authentication. Figure 15 shows the login page, figure 16 and Shows the authentication details of new user through Email and SMS..

\begin{tabular}{|c|c|}
\hline 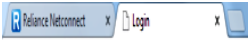 & 0,0 \\
\hline 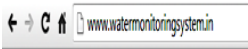 & 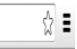 \\
\hline 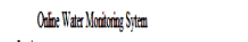 & \\
\hline - $\log -$ & \\
\hline lestlinex & \\
\hline Pussunt & \\
\hline 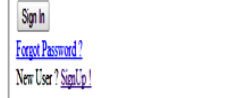 & \\
\hline
\end{tabular}

Fig. 14: Log in screen

Fig. 15: Authentication details of new user through Email

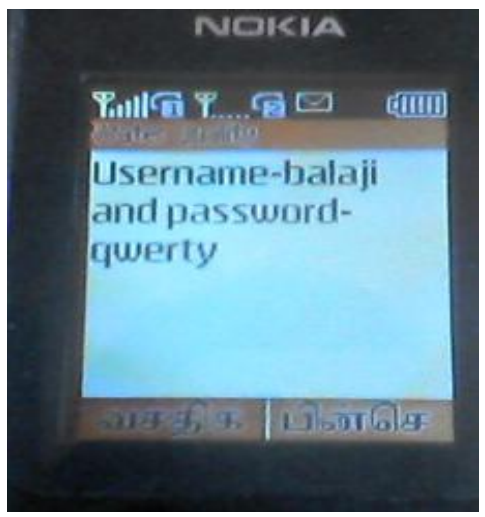

Fig. 16: Authentication details of new user through SMS

Home page of Water Monitoring system is shown in the figure 17. The online monitoring is done " $\mathrm{N}$ " number of remote system. An URL for monitoring the water quality is "www.watermonitoringsystem.in". The sensor values of the water parameters were received from monitoring station module through Zig-Bee. The database of sensed parameters is maintained in the backend of the webpage. The quality of water is viewed by clicking "view parameter choice" link. The report is viewed by clicking "water parameter report" link. Password can be modified by the authenticated user while going into the link "modification word choice".

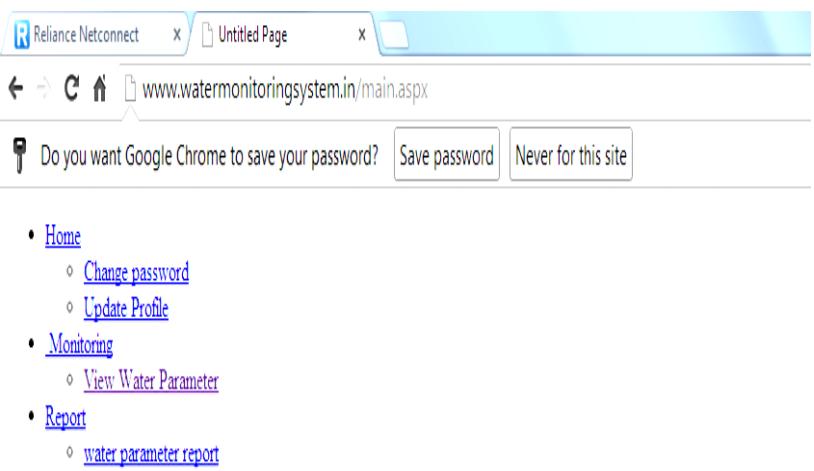

Fig. 17: Home page of Water Monitoring system
The Corresponding date and time will be shown along with the sensor parameter in database and is shown in the figure 18. Water quality is checked by the sensors, if it is below to the set point, the alert information is forwarded to the user. Also it is highlighted separately in the website, which helps the user to alert about the low water quality and made them to do some remedy actions to reduce the forthcoming problem.

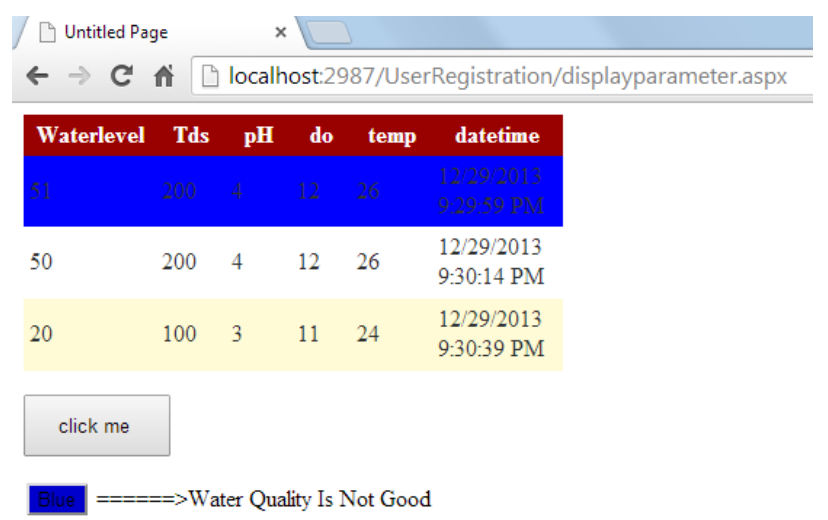

Fig. 18: web page for viewing water parameter

The alert message "Water quality is not good" is provided through email and SMS. In Email the user may not enter the link into the address bar. They can simply click the link which was sent along with the mail, its directly goes to the Water monitoring system's home page instantly. And it is shown in the figure 19 and figure 20.

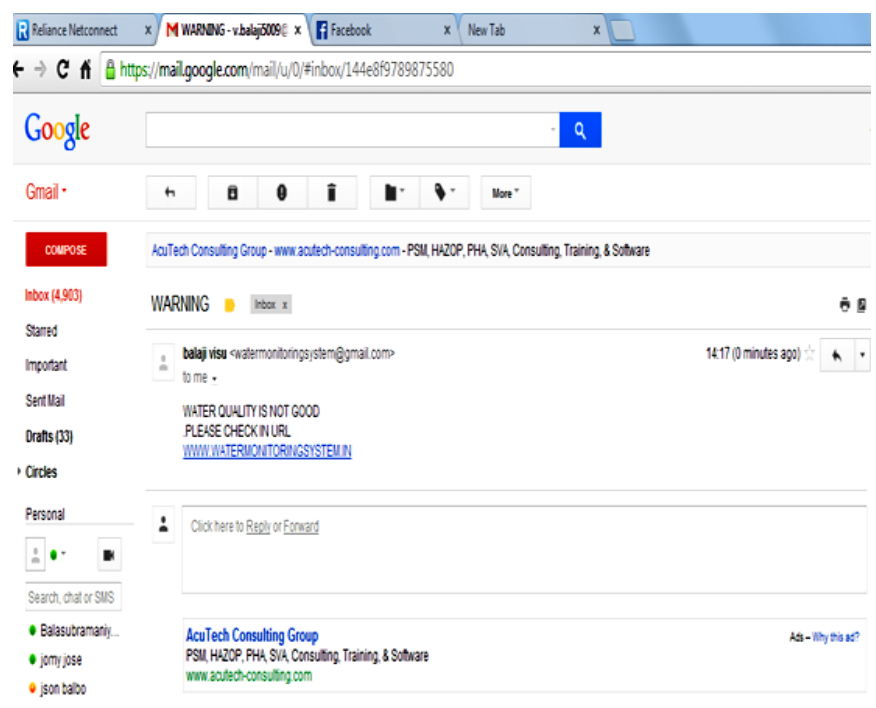

Fig. 19: Email alert to user

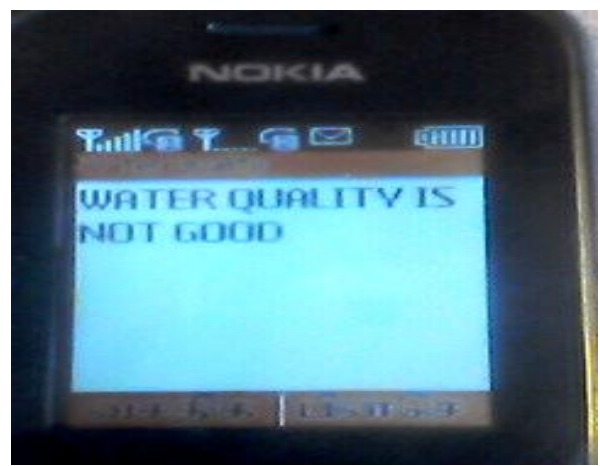

Fig. 20: SMS alert to user 


\section{CONCLUSION}

An embedded system for observance and alert regarding the water contamination of underground and fish pond. This system provides the distinctive advantage to aware about the water contamination and monitoring the water quality mechanically, The system can monitor water quality automatically, and it is low in cost and does not require people with on-site duty. So the water quality testing is likely to be more economical, convenient and fast. In future the water characteristics can be analyzed by considering more physical and biological characteristics of water.

\section{REFERENCES}

[1] Xiao Ying "The Automatic Monitoring Device of Ground water Level Based on Embedded Systems", International Symposium on Information Processing (ISIP'09), pp. 241-244. ,2009

[2] Mo Deqing "Automatic Measurement and Reporting System of Water Quality Based on GSM", Second International Conference on Intelligent System Design and Engineering Application, pp.1007-1010.,2012

[3] Zhang Feng ,"Research on water-saving irrigation automatic control system based on Internet of things", IEEE.,2012
[4] Harshwardhan V. Kharpate," Implementation Of Embedded System For Drinking Water Testing Based On Wsn" , International Journal Of Pure And Applied Research In Engineering And Technology( IJPRET),pp. 30-40.,2013

[5] Haifeng Li, "Water Enviroment Monitoring System Based on Zigbee Technology", Third International Conference on Intelligent System Design and Engineering Applications,pp.1607-1609., 201

[6] R. Balaji, “ Remote Water Pollution Monitoring System Using GSM", UACEE International Journal of Computer Science and its Applications, pp.21-25.

[7] Adinya John Odey ,"AquaMesh - design and implementation of smart wireless mesh sensor networks for aquaculture", American Journal of Networks and Communications, pp.81-87., 2013

[8] Xiuna Zhu ,"A remote wireless system for water quality online monitoring in intensive fish culture", Computers and Electronics in Agriculture,pp.s3-s9., 2010

[9] M.R.Rahimibashar ,"Environment Effects of Fish Culture Pond on Chemical Factors and Water Quality in the Shenrod River (North of Iran)", J. Appl. Environ. Biol. Sci., pp. 358-363., 2012 